\title{
A CONTRIBUIÇÃO DA CIÊNCIA DA INFORMAÇÃO PARA A PRESERVAÇÃO DE IMAGENS DIGITAIS: UMA ANÁLISE DA PRODUÇÃO CIENTÍFICA RECENTE
}

\author{
THE CONTRIBUTION OF INFORMATION SCIENCE \\ TO THE DIGITAL PRESERVATION OF IMAGES: \\ ANALYSIS OF THE RECENT SCIENTIFIC PRODUCTION
}

\section{Luciana Aparecida de Lima Castilho Vânia Mara Alves Lima}

Resumo: Nos últimos anos, em todo o mundo, é possível observar um aumento significativo de iniciativas de digitalização e disponibilização de acervos imagéticos na web. Tais iniciativas possuem como objetivo principal dar visibilidade a esses acervos (antes armazenados com o principal intuito de sua preservação), fazendo com que usuários de todo o mundo possam ter acesso a alguns tesouros por tempos escondidos ou cujo acesso era limitado a um número restrito de pessoas. Paralelamente, uma grande quantidade de imagens geradas e compartilhadas digitalmente todos os dias geram questões e criam desafios sobre a garantia de preservação dessa informação nato-digital disponível online. A preservação de documentos digitais é uma preocupação importante para a memória da humanidade. $\mathrm{O}$ objetivo da pesquisa em andamento é identificar qual tem sido a contribuição da Ciência da Informação no que diz respeito à preservação de imagens digitais por meio de análise da produção científica brasileira recente da área.

Palavras-chave: Ciência da informação. Imagens digitais. Preservação digital

Abstract: Lately, worldwide, it is possible to observe a significant increase of initiatives of digitization and availability of image collections online. These initiatives have as main objective to give visibility to these collections (previously kept with the main intention of their preservation), causing users from all over the world to have access to some treasures hidden for years or whose access was limited to a restricted number of people. At the same time, a large amount of digitally generated and shared images raise questions and create challenges for how to ensuring the preservation of this born-digital information available online. The preservation of digital documents is important for the memory of mankind. The objective of the ongoing research is to identify the contribution of Information Science in the preservation of digital images through the analysis of the recent Brazilian scientific production of the area.

Keywords: Digital images. Digital preservation. Information Sciences

\section{Introdução}

O impulso de preservação da memória por meio de imagens pode ser observado desde as pinturas rupestres, passando pela descoberta da fotografia (onde o intuito principal foi o de fixar a imagem em um suporte passível de preservação para a posteridade) e chegando a atualidade, onde milhares de bytes são gerados segundo a segundo com imagens do cotidiano. 
VI Seminário de Pesquisa em Ciência da Informação do PPGCI 2017

Escola de Comunicações e Artes - Universidade de São Paulo

Se uma fotografia de família do início do século XIX é hoje objeto de estudo e pesquisa, conservada em seu suporte original e digitalizada para acesso e divulgação, como garantir que essa imagem do início do século XXI, gerada digitalmente, esteja disponível para pesquisadores do próximo século?

Quanto da produção de imagens contemporâneas poderá ser localizada em dez anos? Se pensarmos que há dez anos o disquete e o CD-ROM eram as mídias de armazenamento mais comuns e que as ferramentas de rede social mais utilizadas na década passada, como, Fotolog e Orkut, já não estão disponíveis online, talvez a resposta seja quase nada.

Diante de um cenário quase que apocalíptico, é necessário mapear e compreender as iniciativas e necessidades de pesquisa no campo da preservação de imagens digitais. A pesquisa em andamento pretende verificar qual tem sido a contribuição da Ciência da Informação nesse campo, tentando identificar também novas possibilidades de pesquisa.

\section{Metodologia}

O procedimento metodológico prevê uma revisão de literatura sobre o objeto de estudo definido, ou seja, preservação digital de imagens.

Partindo de uma análise quantitativa da produção científica brasileira sobre preservação digital, serão identificadas as que foram realizadas no âmbito dos Programas de Pós-graduação em Ciência da Informação e, dentre elas, as que tratem de forma direta ou indireta de preservação de imagens digitais.

Em seguida, serão analisados os conteúdos das produções previamente localizadas tentando identificar ainda se há uma preocupação em distinguir as questões referentes à preservação de imagens digitalizadas e nato-digitais.

\section{Discussão e referencial teórico}

De acordo com Sayão (2012), a mesma tecnologia que permite a criação, manipulação, armazenamento e disponibilização de uma quantidade impressionante de informações, coloca em perigo a longevidade dos objetos informacionais por ela engendrada, colocando a humanidade face a face com o perigo de uma amnésia digital iminente, uma vez que os objetos digitais requerem metodologias de gestão que são muito diferentes das que são utilizadas no universo da impressão tradicional.

Com a possibilidade de geração de muitas imagens a um custo quase zero, a quantidade de imagens online cresce exponencialmente, nesse exato momento milhões de 
VI Seminário de Pesquisa em Ciência da Informação do PPGCI 2017

Escola de Comunicações e Artes - Universidade de São Paulo

pessoas no globo têm acesso à smartphones com câmera e internet, e milhares de fotografias estão sendo publicadas nas ferramentas de redes sociais. Para Santaella (1999), a fotografia digital introduziu modificações minimizando a ênfase no objeto e sobrando à foto a função de mera testemunha do passageiro. Assim, a quantidade de lixo digital criado também cresce na mesma proporção de modo que faria sentido pensar em guardar tudo o que é produzido como uma forma de garantir a preservação?

Pereira (2012) alerta que em meio a grande quantidade de informação digital a tentativa de preservação integral pode, ao contrário, fazer com que haja uma má-informação sobre o tempo atual quando este tornar-se passado. Segundo o autor:

[...]é tão urgente estabelecer critérios para a gestão eficiente dos documentos digitais, com visas à diminuição do chamado 'lixo digital', quanto garantir as condições tecnológicas que nos permitam utilizar aqueles documentos no futuro.

No entanto, é um erro pensar que apenas a ação de guardar um determinado arquivo de forma que ele seja passível de acesso no futuro seja uma garantia de preservação digital. De acordo com Innarelli ( 2007), a preservação digital é um assunto complexo e que não deve ser restrito ao estudo das mídias, técnicas de backup, técnicas de migração, técnicas de autenticação, etc. Para o autor, esse é um assunto que deve ser estudado de forma interdisciplinar e institucionalmente.

O tratamento de coleções imagéticas é, desde o início, um desafio para os profissionais da informação. Em artigo sobre representação da imagem fotográfica, Smith (1996) conclui que é imprescindível desenvolver procedimentos transparentes para o usuário final quanto ao tratamento de representação dado às imagens, uma vez que elas são polissêmicas e que há uma imprevisibilidade em relação ao seu uso. Se considerarmos a imagem digital a questão é ampliada uma vez que um arquivo digital não pode ser visto sem o intermédio de um software e hardware e que pode estar ainda mais suscetível à identificação equivocada, já que é frequentemente descrita de maneira pobre (rótulo e metadados incompletos) e, portanto, por vezes difícil de rastrear.

Considerando o grande volume de imagens produzidos atualmente e as dificuldades de identificação que o documento digital pode colocar em questão, é necessário que os profissionais da informação estejam preparados para encarar uma nova realidade, sendo necessário até mesmo compreender e criar novas formas de análises desses dados.

Segundo Gouveia e Carreira (2014, p.100-101):

"O caráter numérico de qualquer arquivo digital é justamente o que permite que hoje sejam desenvolvidas análises de gigantescos conjuntos de dados - os chamados Big Data. O termo que adquire destaque cada vez maior na mídia e no meio acadêmico, designa um grande volume de dados que requer não somente tecnologias 
VI Seminário de Pesquisa em Ciência da Informação do PPGCI 2017

Escola de Comunicações e Artes - Universidade de São Paulo

determinadas (como dispositivos com maior capacidade de processamento e armazenamento, softwares de extração e visualização, etc.), mas também métodos e profissionais especializados."

Faz sentido que a área de Ciência da Informação possa contribuir na elaboração e desenvolvimento de tais métodos, e também que os profissionais da informação estejam diretamente envolvidos com essas ações.

\section{Considerações finais}

São diversas as questões que precisam ser respondidas no âmbito da preservação digital, em especial de imagens, questões essas que impactam diretamente no trabalho dos profissionais da informação.

Por meio da realização de um mapeamento de como essas questões estão sendo tratadas pela área de Ciência da Informação, será possível identificar como a discussão desse tema tem sido encarada pelos profissionais brasileiros de instituições como bibliotecas, arquivos e museus.

Supondo ainda que seja necessário distinguir metodologias distintas no que diz respeito à preservação de imagens digitalizadas e das nato-digitais, a pesquisa em andamento poderá contribuir ao trazer essa discussão para uma reflexão de caráter empírico no momento que deixa de encarar todos os objetos digitais de uma mesma maneira e tenta alertar para as diferenças inerentes a cada um deles.

\section{Agradecimentos}

Agradecimento à CAPES, pela concessão de bolsa de estudos à Luciana Ap. de L. Castilho.

\section{Referências}

ACADEMY OF MOTION PICTURE ARTS AND SCIENCES. O dilema digital. São Paulo: Cinemateca Brasileira, 2009.

GOUVEIA, F. G. ; CARREIRA, L.S. Fotografia e Big Data: implicações metodológicas. In: BONI, P.C. (org.) Fotografia: usos, repercussões e reflexões. Londrina: Midiograf, 2014. p. 98-112.

INNARELLI, H. C. Preservação digital e seus dez mandamentos. In: SANTOS, V. B. (Org.). Arquivística: temas contemporâneos, classificação, preservação digital, gestão do conhecimento. Distrito Federal: SENAC, 2013. p. 21-75.

PEREIRA, J.H.M. Preservação digital: desafios para a implantação de procedimentos e políticas eficazes. In: SEMINÁRIO SERVIÇO DE INFORMAÇÃO EM MUSEU, 2., 2012, São Paulo. Anais... São Paulo: Pinacoteca do Estado de São Paulo, 2012. p. 271-279. 
VI Seminário de Pesquisa em Ciência da Informação do PPGCI 2017

Escola de Comunicações e Artes - Universidade de São Paulo

SANTAELLA, L. Imagem. São Paulo: Editora Iluminura, 1999.

SAYÃO, L. F.; SALES, L. F. Curadoria digital: um novo patamar para preservação de dados digitais de pesquisa. Informação \& Sociedade: Estudos, v. 22, n. 3, set./dez. 2012. Disponível em: $<$ http://www.ies.ufpb.br/ojs/index.php/ies/article/view/12224/8586>. Acesso em: 10 set. 2016.

SMITH, J.. W. A representação da imagem. Informare, v. 2, n. 2, jul./dez. 1996.

\section{Sobre as autoras}

Luciana Aparecida de Lima Castilho

Mestranda no PPGCI/ECA/USP

Vânia Mara Alves Lima

Docente no PPGCI/ECA/USP 